\title{
Modelling and experimental investigation of process parameters in WEDM of WC-5.3\% Co using response surface methodology
}

\author{
K. Jangra and S. Grover \\ Department of Mechanical Engineering, YMCA University of Science and Technology, Faridabad 121006, \\ India
}

Correspondence to: K. Jangra (kamaljangra84@gmail.com)

Received: 7 January 2012 - Revised: 18 September 2012 - Accepted: 4 October 2012 - Published: 1 November 2012

\begin{abstract}
Tungsten carbide-cobalt (WC-Co) composite is a difficult-to-machine material owing to its excellent strength and hardness at elevated temperature. Wire electrical discharge machining (WEDM) is a best alternative for machining of WC-Co composite into intricate and complex shapes. Efficient machining of WC-Co composite on WEDM is a challenging task since it involves large numbers of parameters. Therefore, in present work, experimental investigation has been carried out to determine the influence of important WEDM parameters on machining performance of WC-Co composite. Response surface methodology, which is a collection of mathematical and experimental techniques, was utilised to obtain the experimental data. Using face-centered central composite design, experiments were conducted to investigate and correlate the four input parameters: pulse-on time, pulse-off time, servo voltage and wire feed for three output performance characteristics - cutting speed (CS), surface roughness (SR) and radial overcut (RoC). Using analysis of variance on experimental data, quadratic vs. two-factor interaction (2FI) models have been suggested for CS and RoC while two-factor interaction (2FI) has been proposed for SR. Using these mathematical models, optimal parameters can be determined easily for desired performance characteristics, and hence a trade-off can be made among different performance characteristics.
\end{abstract}

\section{Introduction}

Demand for tungsten carbide-cobalt (WC-Co) composite has been growing rapidly due to its excellent mechanical properties like high wear and corrosion resistance, which makes it most suitable for cutting tools, dies and other special wearresisting applications. Machining of WC-Co composite is very difficult with conventional machining processes like turning, milling and grinding (Liu and Li, 2001; Liu et al., 2003; Engqvist et al., 1999; Jia and Fischer, 1997) because of its high hardness and high melting temperature. Due to the low material removal rate and difficulty in machining of complex and intricate profiles in WC-Co composite, cost associated with conventional machining processes is very high.

Wire electrical discharge machining (WEDM) is a specialised form of electrical discharge machining (EDM) process which is potentially used to generate intricate and com- plex geometries in hard conductive materials without making any mechanical contact (Jangra et al., 2010). In WEDM, material is eroded due to the melting/evaporation of work surface which is mainly due to the localised high temperature generation in plasma channel between the work material and downward moving wire electrode (as shown in Fig. 1). In order to achieve high productivity within specified tolerance on WEDM, selection of optimal process parameters plays a key role which depends on large numbers of variables such as composition and grain size of work material, machining parameters, wire electrode material, wire diameter, cutting conditions and work geometry etc. (Jangra et al., 2011).

Several attempts have been made to determine optimal machining conditions for WC-Co composite on EDM and WEDM. Lee and Li (2001) investigated the influence of EDM parameters such as the electrode materials, electrode polarity, open circuit voltage, peak current, pulse duration, 


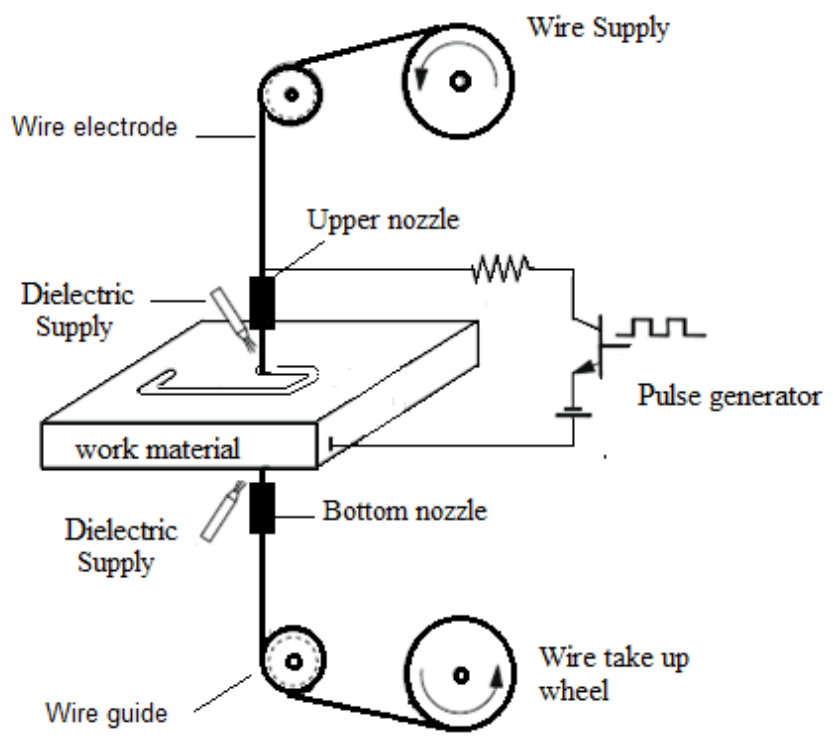

Figure 1. Representation of WEDM process.

pulse interval and flushing on the machining characteristics, such as material removal rate (MRR), surface finish and relative tool wear in EDM of tungsten carbide. Lee and Li (2003) elucidated the effect of discharge energy on integrity of EDMed surface of tungsten carbide. It was found that the surface roughness is a function of two main parameters: peak current and pulse duration. At high peak current and/or long pulse duration, rough surface and abundance of micro-cracks were observed. Mahdavinejad and Mahdavinejad (2005) studied the instability in EDM of WC-Co composites. This machining instability was mainly due to open circuit, short circuit and arcing pulses. Increase in pulse duration results in more melting and recasting of material, which causes arcing and rougher surface.

The grain size of WC and cobalt composition also shows noticeable influence on machining performance of WC-Co composite with WEDM (Kim and Kruth, 2001; Lauwers et al., 2006). Varying the cobalt concentration and grain size of WC alters the thermal conductivity of the material, which affects the machining performance. Chen et al. (2010) utilised Taguchi method, back propagation neural network and genetic algorithm to optimize the WEDM parameters in machining of pure tungsten. Pulse-on time was the most significant parameter that influences both the cutting speed and surface roughness. Jangra et al. (2012) optimized the multimachining characteristics in WEDM of WC-5.3\% Co composite using an integrated approach of Taguchi, GRA and entropy method. Six input parameters - taper angle, discharge current, pulse-on time, pulse-off time, wire tension and dielectric flow rate - were investigated for four output machining characteristics: MRR, SR, RoC and angular error.

Although WEDM can easily machine complex profiles in WC-Co composite but damaged work surface consisting of recast layer, large micro-cracks are a major concern in WEDM (Çaydaş et al., 2009; Jangra, 2012). In order to obtain fine surface finish and low surface defects, low discharge parameters with high dielectric flushing rate are required. but they lower the cutting rate in WEDM. This implies that high cutting rate with low surface roughness and minimum surface defects is difficult to obtain in a single setting of process parameters. In order to achieve an efficient machining of WC-Co composite into desired shape, inter-relationship (mathematical modelling) between input WEDM parameters and output performance characteristics should be available to the manufacturers, so that a trade-off can be made among various performance characteristics.

Two kinds of approaches, theoretical and empirical, have been commonly used in modelling of WEDM process (Patil and Brahmankar, 2010). Owing to the simplified and unavoidable assumptions, the theoretical models yield large errors between predicted and experimental results. On the other hand empirical models are limited to specific experimental conditions. Response surface methodology (RSM) is the most used statistical technique for determining the relationship between various input parameters and output responses (Myers and Montgomery, 1995; Hewidy et al., 2005; Kansal et al., 2005). RSM is a collection of mathematical and experimental techniques that requires sufficient number of experimental data to analyse the problem and to develop mathematical models for several variables and output performance characteristics.

Because the WEDM involves multi-performance characteristics, the objective of the present study is to investigate the influence of process parameters and to develop the mathematical models for three performance characteristics namely cutting speed (CS), surface roughness (SR) and radial overcut (RoC) in WEDM of WC-5.3\% Co composite. Response surface methodology with face-centered central composite design has been utilised to conduct the experimentation which helps to investigate and to correlate the input parameters with output performance characteristics. Using these mathematical models, optimal combination of WEDM parameters can be selected for desired performance characteristics for WC-Co composite.

\section{Experimental procedure}

\subsection{Work material and machining parameters}

Tungsten carbide composite with low cobalt concentration $(5.3 \%)$ has been taken as a work material in the form of a rectangular block of thickness of $13 \mathrm{~mm}$. The density and hardness of WC-5.3\% Co composite were measured as $14.95 \mathrm{~g} \mathrm{~cm}^{-3}$ and $77 \mathrm{HRC}$, respectively.

Experiments were performed on 5-axis sprint cut (epulse40) WEDM, most widely used in Indian industries, manufactured by Electronica Machine Tools Ltd., India. In present machine tool, range of the important parameters is as 
Table 1. Process parameters and their levels.

\begin{tabular}{clccc}
\hline Symbol & Parameters & \multicolumn{3}{c}{ Levels } \\
& & $(-1)$ & $(0)$ & $(+1)$ \\
\hline A & Pulse-on Time $\left(T_{\text {on }}\right)$ & 108 & 115 & 122 \\
B & Pulse-off Time $\left(T_{\text {off }}\right)$ & 30 & 40 & 50 \\
C & Servo Voltage $(S V)$ & 20 & 30 & 40 \\
D & Wire Feed Rate $(\mathrm{WF})$ & 4 & 6 & 8 \\
\hline
\end{tabular}

follows: discharge current, 10-230 amp; pulse-on time, 101$131 \mu$ s; pulse-off time, $10-63 \mu \mathrm{s}$; servo voltage 0-90 V; dielectric flow rate, $0-12$ litre per minute $\left(\mathrm{min}^{-1}\right)$; wire feed, 1-15 $\mathrm{m} \mathrm{min}^{-1}$; wire tension, $1-15 \mathrm{~N}$.

In present investigation, four important WEDM parameters, namely pulse-on time $\left(T_{\text {on }}\right)$, pulse-off time $\left(T_{\text {off }}\right)$, servo voltage (SV) and wire feed (WF) have been considered with three levels each (Table 1). Discharge current is kept at optimum value of $90 \mathrm{amp}$ which is taken on the basis of earlier investigations (Jangra et al., 2011, 2012). Similarly, other parameters were kept constant at their optimal values. As the workpiece thickness is low $(13 \mathrm{~mm})$, wire tension was kept fixed at $10 \mathrm{~N}$. Zinc-coated brass wire of diameter $0.25 \mathrm{~mm}$ was used as an electrode because of its good capability to sustain high discharge energy. High flow rate results in quick and complete flushing of melted debris out of the spark gap. Therefore, dielectric flow rate is kept at maximum value of $121 \mathrm{~min}^{-1}$. Vertical cutting was performed at zero wire offset.

\subsection{Performance characteristics}

CS was measured as surface area removed per minute $\left(\mathrm{mm}^{2} \mathrm{~min}^{-1}\right)$. It was obtained by multiplying the workpiece thickness $(13 \mathrm{~mm})$ with linear cutting speed $\left(\mathrm{mm} \mathrm{min}^{-1}\right)$ displaying on machine tool monitor screen. Surface roughness is a good indicator of the surface quality which can be easily measured by a tool manufacturer. In present work, SR value (in $\mu \mathrm{m}$ ) was measured in terms of mean absolute deviation (Ra) using the digital surface tester Mitutoyo 201P. RoC (in $\mu \mathrm{m}$ ) is the gap between machined work surface and wire periphery (as shown in Fig. 2). "D" represents the wire diameter. $\mathrm{RoC}$ helps to predict accurate wire offset for precise dimensional tolerance. Neglecting the wire lag compensation for straight cutting, wire offset is given by the sum of wire radius and RoC (Sarkar et al., 2008). RoC was measured using optimal microscope.

\subsection{Experimental design using RSM}

For developing an adequate relationship between input WEDM parameters and output performance characteristics, response surface methodology (RSM) (Myers and Montgomery, 1995) has been employed. By using the design of experiments and applying regression analysis, the modelling of the desired response $(Y)$ to several independent input vari-

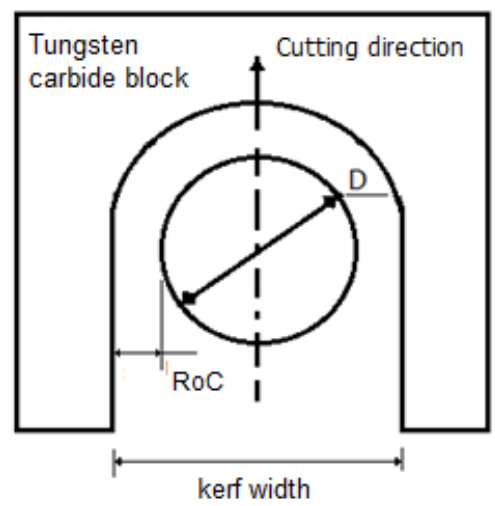

Figure 2. Representation of RoC in WEDM.

ables $\left(x_{i}\right)$ can be gained. In the RSM, the quantitative form of relationship between desired response and independent input variables could be represented as

$Y=\Phi\left(x_{1}, x_{2}, \ldots \ldots \ldots, x_{k}\right) \pm e_{\mathrm{r}}$.

The function $\Phi$ is called response surface or response function. The residual $e_{\mathrm{r}}$ measures the experimental errors (Cochran and Cox, 1962).

In applying the RSM, the dependent variable is viewed as a surface to which a mathematical model is fitted. For the development of regression equations related to various performance characteristics of WEDM process, the second-order response surface has been assumed as

$Y=b_{0}+\sum_{i=1}^{k} b_{i} X_{i}+\sum_{i=1}^{k} b_{i i} X_{i}^{2}+\sum_{i<j=2}^{2} b_{i j} X_{i} X_{j} \pm e_{\mathrm{r}}$.

This assumed surface $Y$ contains linear, squared and cross product terms of variables $X_{i}$. The model parameters can be estimated most effectively if proper experimental designs are used to collect the data. In present case, a standard secondorder experimental design called face-centered central composite design (CCD) has been adopted for analysing and modelling four input parameters. This design consists of factorial portion with all parameters at three levels, eight star points and six central points. The star points are at the face of the cube portion on the design which corresponds to $\alpha$-value of 1 , the distance from design centre. The centre points, as implied by the name, are points with all levels set to coded level 0 , the midpoint of each parameter range. Table 2 shows the experimental conditions.

\section{Results and discussion}

The 30 experiments were conducted and CS, SR and RoC were obtained for each experimental run (as listed in Table 2). 
Table 2. Test conditions in face-centered central composite design.

\begin{tabular}{|c|c|c|c|c|c|c|c|c|c|c|c|}
\hline \multirow{2}{*}{$\begin{array}{r}\text { Trial } \\
\text { No. }\end{array}$} & \multicolumn{2}{|c|}{$\mathrm{A}\left(T_{\text {on }}\right)$} & \multicolumn{2}{|c|}{$\mathrm{B}\left(T_{\text {off }}\right)$} & \multicolumn{2}{|c|}{$\mathrm{C}(\mathrm{SV})$} & \multicolumn{2}{|c|}{$\mathrm{D}(\mathrm{WF})$} & \multirow{2}{*}{$\begin{array}{l}\mathrm{CS} \\
\left(\mathrm{mm} \mathrm{min}{ }^{-1}\right)\end{array}$} & \multirow{2}{*}{$\begin{array}{l}\text { SR } \\
(\mu \mathrm{m})\end{array}$} & \multirow{2}{*}{$\begin{array}{l}\text { RoC } \\
(\mu \mathrm{m})\end{array}$} \\
\hline & coded & actual & coded & actual & coded & actual & coded & actual & & & \\
\hline 1 & -1 & 108 & -1 & 30 & -1 & 20 & -1 & 4 & 16.691 & 1.51 & 16.97 \\
\hline 2 & 1 & 122 & -1 & 30 & -1 & 20 & -1 & 4 & 27.97 & 2.2 & 19.78 \\
\hline 3 & -1 & 108 & 1 & 50 & -1 & 20 & -1 & 4 & 6.52 & 1.104 & 19.03 \\
\hline 4 & 1 & 122 & 1 & 50 & -1 & 20 & -1 & 4 & 14.22 & 1.78 & 21.35 \\
\hline 5 & -1 & 108 & -1 & 30 & 1 & 40 & -1 & 4 & 16.59 & 1.2 & 16.87 \\
\hline 6 & 1 & 122 & -1 & 30 & 1 & 40 & -1 & 4 & 27.88 & 1.9 & 19.45 \\
\hline 7 & -1 & 108 & 1 & 50 & 1 & 40 & -1 & 4 & 6.29 & 0.84 & 18.68 \\
\hline 8 & 1 & 122 & 1 & 50 & 1 & 40 & -1 & 4 & 14.12 & 1.52 & 21.05 \\
\hline 9 & -1 & 108 & -1 & 30 & -1 & 20 & 1 & 8 & 18.57 & 1.4 & 17.87 \\
\hline 10 & 1 & 122 & -1 & 30 & -1 & 20 & 1 & 8 & 32.58 & 2.02 & 21.61 \\
\hline 11 & -1 & 108 & 1 & 50 & -1 & 20 & 1 & 8 & 8.4 & 1.01 & 19.46 \\
\hline 12 & 1 & 122 & 1 & 50 & -1 & 20 & 1 & 8 & 16.36 & 1.7 & 22.08 \\
\hline 13 & -1 & 108 & -1 & 30 & 1 & 40 & 1 & 8 & 16.53 & 1.17 & 16.98 \\
\hline 14 & 1 & 122 & -1 & 30 & 1 & 40 & 1 & 8 & 30.54 & 1.86 & 20.56 \\
\hline 15 & -1 & 108 & 1 & 50 & 1 & 40 & 1 & 8 & 5.12 & 0.81 & 18.77 \\
\hline 16 & 1 & 122 & 1 & 50 & 1 & 40 & 1 & 8 & 14.32 & 1.5 & 22.09 \\
\hline 17 & -1 & 108 & 0 & 40 & 0 & 30 & 0 & 6 & 12.01 & 1.14 & 17.58 \\
\hline 18 & 1 & 122 & 0 & 40 & 0 & 30 & 0 & 6 & 22.25 & 1.82 & 21.22 \\
\hline 19 & 0 & 115 & -1 & 30 & 0 & 30 & 0 & 6 & 24.8 & 1.66 & 18.83 \\
\hline 20 & 0 & 115 & 1 & 50 & 0 & 30 & 0 & 6 & 12.22 & 1.3 & 20.23 \\
\hline 21 & 0 & 115 & 0 & 40 & -1 & 20 & 0 & 6 & 19.04 & 1.61 & 19.96 \\
\hline 22 & 0 & 115 & 0 & 40 & 1 & 40 & 0 & 6 & 17.97 & 1.35 & 19.6 \\
\hline 23 & 0 & 115 & 0 & 40 & 0 & 30 & -1 & 4 & 17.99 & 1.55 & 19.56 \\
\hline 24 & 0 & 115 & 0 & 40 & 0 & 30 & 1 & 8 & 19.03 & 1.39 & 20.32 \\
\hline 25 & 0 & 115 & 0 & 40 & 0 & 30 & 0 & 6 & 18.35 & 1.48 & 19.82 \\
\hline 26 & 0 & 115 & 0 & 40 & 0 & 30 & 0 & 6 & 18.69 & 1.5 & 19.76 \\
\hline 27 & 0 & 115 & 0 & 40 & 0 & 30 & 0 & 6 & 18.87 & 1.46 & 19.89 \\
\hline 28 & 0 & 115 & 0 & 40 & 0 & 30 & 0 & 6 & 18.48 & 1.48 & 20.01 \\
\hline 29 & 0 & 115 & 0 & 40 & 0 & 30 & 0 & 6 & 18.54 & 1.47 & 19.8 \\
\hline 30 & 0 & 115 & 0 & 40 & 0 & 30 & 0 & 6 & 18.08 & 1.51 & 19.58 \\
\hline
\end{tabular}

\subsection{Mathematical model for CS, SR and RoC}

Using the experimental data, regression equations have been developed for correlating the output performance characteristics and input WEDM parameters. Analysis of variance (ANOVA) has been applied on the experimental data to select the adequate model. Design expert (DX8), a statistical tool, has been utilised to analyse the experimental data. Quadratic vs. two-factor interaction (2FI) models have been suggested for CS and RoC, while two-factor interaction (2FI) has been proposed for SR. Table 3 shows the fit summary for proposed models.

In Table 3, a p-value for the model terms that are less than 0.05 (i.e. $\alpha=0.05$, or $95 \%$ confidence level) indicates that the obtained models are considered to be statistically significant (Kanagarajan et al., 2008). It shows that the terms in the model have significant effect on responses. From Table 3, coefficient of determination $\left(R^{2}\right)$ and $R^{2}$ (adj.) for all three responses are closer to unity, which is desirable for the re- sponse model to fit the actual data. The lack of fit is a measure of the failure of the model to predict the data in the upper and lower limits of the parameters. The "lack of fit" for all three characteristics is insignificant because of high probability value (F-value), which is desirable for selecting the models. Figures 3 to 5 show that the residuals are normally distributed about a straight line and there is no problem with the observed results. Consequently, the proposed models for three responses can be considered as significant for fitting and predicting the experimental results within the specified experimental domain.

Table 4 shows the "F-value" and "p-value" for each term in performance characteristics CS, SR and RoC, respectively. The terms having p-value less than 0.05 are considered to be significant while insignificant terms can be eliminated from the final predicted models. In case of CS, the model terms A, $\mathrm{B}, \mathrm{C}, \mathrm{D}, \mathrm{AB}, \mathrm{AD}, \mathrm{BD}, \mathrm{CD}$ and $\mathrm{A}^{2}$ are significant. Similarly, $\mathrm{A}, \mathrm{B}, \mathrm{C}, \mathrm{D}$ and $\mathrm{CD}$ for SR, and $\mathrm{A}, \mathrm{B}, \mathrm{C}, \mathrm{D}, \mathrm{AB}, \mathrm{AD}$ and $\mathrm{A}^{2}$ for $\mathrm{RoC}$ are significant model terms. 
Table 3. The ANOVA table for fitted models.

\begin{tabular}{|c|c|c|c|c|c|c|}
\hline Source & $\begin{array}{l}\text { Sum of } \\
\text { Squares }\end{array}$ & $\begin{array}{l}\text { Degree of } \\
\text { freedom }\end{array}$ & $\begin{array}{l}\text { Mean } \\
\text { Square }\end{array}$ & F-value & p-value & \\
\hline \multicolumn{7}{|l|}{ (a) For CS } \\
\hline Model & 1277.4 & 14 & 91.24 & 771.23 & $<0.0001$ & Significant \\
\hline Residual & 1.774 & 15 & 0.118 & & & \\
\hline Lack of fit & 1.401 & 10 & 0.140 & 1.873 & 0.2532 & Not significant \\
\hline Pure error & 0.374 & 5 & 0.074 & & & \\
\hline Cor. total & 1279.17 & 29 & & & & \\
\hline \multicolumn{7}{|c|}{ Standard deviation $=0.34396 ; R^{2}=0.9986 ; R^{2}($ Adj. $)=0.9973$} \\
\hline \multicolumn{7}{|l|}{ (b) For SR } \\
\hline Model & 3.0092 & 10 & 0.3009 & 680.53 & $<0.0001$ & Significant \\
\hline Residual & 0.0084 & 19 & 0.0004 & & & \\
\hline Lack of fit & 0.0066 & 14 & 0.00047 & 1.374 & 0.3859 & Not significant \\
\hline Pure error & 0.0017 & 5 & 0.00034 & & & \\
\hline Cor. Total & 3.0175 & 29 & & & & \\
\hline \multicolumn{7}{|c|}{ Standard deviation $=0.02229 ; R^{2}=0.9972 ; R^{2}($ Adj. $)=0.9957$} \\
\hline \multicolumn{7}{|l|}{ (c) For RoC } \\
\hline Model & 56.653 & 14 & 4.0466 & 89.536 & $<0.0001$ & Significant \\
\hline Residual & 0.678 & 15 & 0.0452 & & & \\
\hline Lack of fit & 0.576 & 10 & 0.0576 & 2.823 & 0.1318 & Not significant \\
\hline Pure error & 0.102 & 5 & 0.0204 & & & \\
\hline Cor. Total & 57.33 & 29 & & & & \\
\hline Standard de & ion $=0.2$ & $26 ; R^{2}=0$ & $31 ; R^{2}(\mathrm{~A}$ & $=0.9$ & & \\
\hline
\end{tabular}

Table 4. F-value and p-value for each model term for CS, SR and RoC.

\begin{tabular}{lrrrlrlr}
\hline $\begin{array}{l}\text { Source/ } \\
\text { Symbol }\end{array}$ & DOF & \multicolumn{2}{c}{ CS } & \multicolumn{2}{c}{ SR } & \multicolumn{2}{c}{ RoC } \\
& & F-value & p-value & F-value & p-value & F-value & p-value \\
\hline A & 1 & 4106.921 & $<0.0001$ & 4699.663 & $<0.0001$ & 894.779 & $<0.0001$ \\
B & 1 & 6165.125 & $<0.0001$ & 1415.063 & $<0.0001$ & 234.773 & $<0.0001$ \\
C & 1 & 56.727 & $<0.0001$ & 599.29 & $<0.0001$ & 20.262 & 0.0004 \\
D & 1 & 81.560 & $<0.0001$ & 69.546 & $<0.0001$ & 60.232 & $<0.0001$ \\
AB & 1 & 169.249 & $<0.0001$ & 0.1832 & 0.6735 & 5.983 & 0.0273 \\
AC & 1 & 1.0075 & 0.3314 & 0.9973 & 0.3305 & 0.179 & 0.6781 \\
AD & 1 & 26.488 & 0.0001 & 0.4433 & 0.5136 & 13.984 & 0.0020 \\
BC & 1 & 1.0046 & 0.3321 & 0.8164 & 0.3775 & 1.4957 & 0.2402 \\
BD & 1 & 19.266 & 0.0005 & 2.6143 & 0.1224 & 3.8106 & 0.0699 \\
CD & 1 & 41.648 & $<0.0001$ & 16.7263 & 0.0006 & 3.2796 & 0.0902 \\
$\mathrm{~A}^{2}$ & 1 & 43.014 & $<0.0001$ & - & - & 5.9025 & 0.0282 \\
$\mathrm{~B}^{2}$ & 1 & 0.0101 & 0.9213 & - & - & 2.0886 & 0.1690 \\
$\mathrm{C}^{2}$ & 1 & 0.0153 & 0.9030 & - & - & 0.2004 & 0.6608 \\
$\mathrm{D}^{2}$ & 1 & 0.0101 & 0.9213 & - & - & 2.7525 & 0.1179 \\
\hline
\end{tabular}




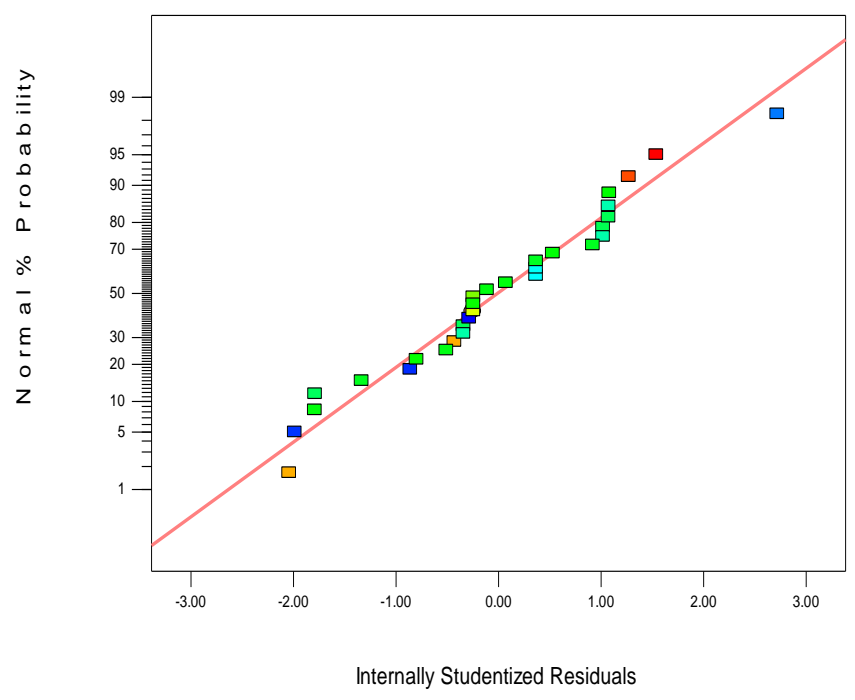

Figure 3. Residuals plot for CS.

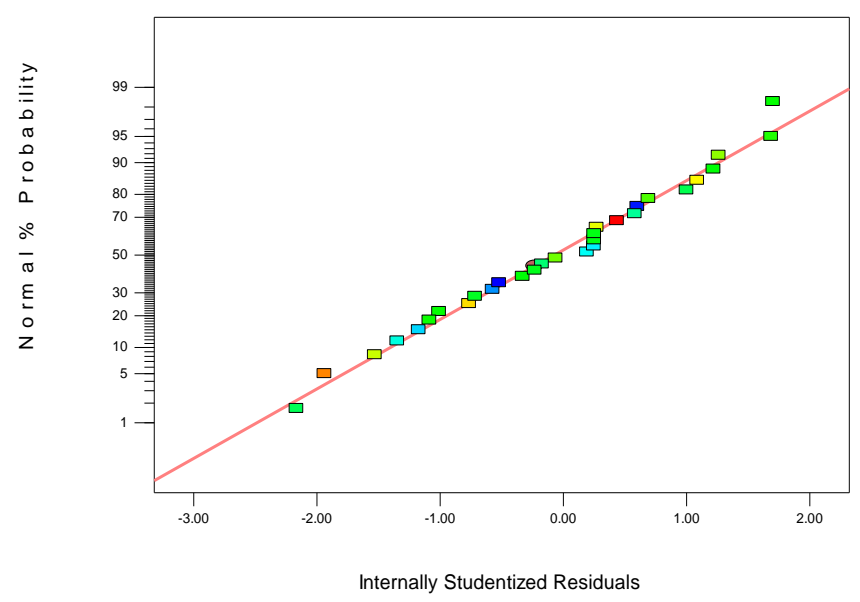

Figure 4. Residuals plot for SR.

Using backward elimination method, non-significant terms were eliminated. Final regression equations for performance characteristics have been obtained as follows.

\subsubsection{Cutting speed (CS)}

Regression equation is in terms of coded parameters:

$$
\begin{aligned}
\mathrm{CS} & =18.51+5.20 \mathrm{~A}-6.37 \mathrm{~B}-0.61 \mathrm{C}+0.73 \mathrm{D} \\
& -1.12 \mathrm{AB}+0.44 \mathrm{AD}-0.38 \mathrm{BD}-0.55 \mathrm{CD}-1.45 \mathrm{~A}^{2}
\end{aligned}
$$

Regression equation is in terms of actual parameters:

$$
\begin{aligned}
\mathrm{CS} & =-494.76+8.0055 \mathrm{~A}+1.314 \mathrm{~B}+0.1054 \mathrm{C}-1.682 \mathrm{D} \\
& -0.01598 \mathrm{AB}+0.031612 \mathrm{AD}-0.01887 \mathrm{BD} \\
& -0.02774 \mathrm{CD}-0.0296 \mathrm{~A}^{2}
\end{aligned}
$$

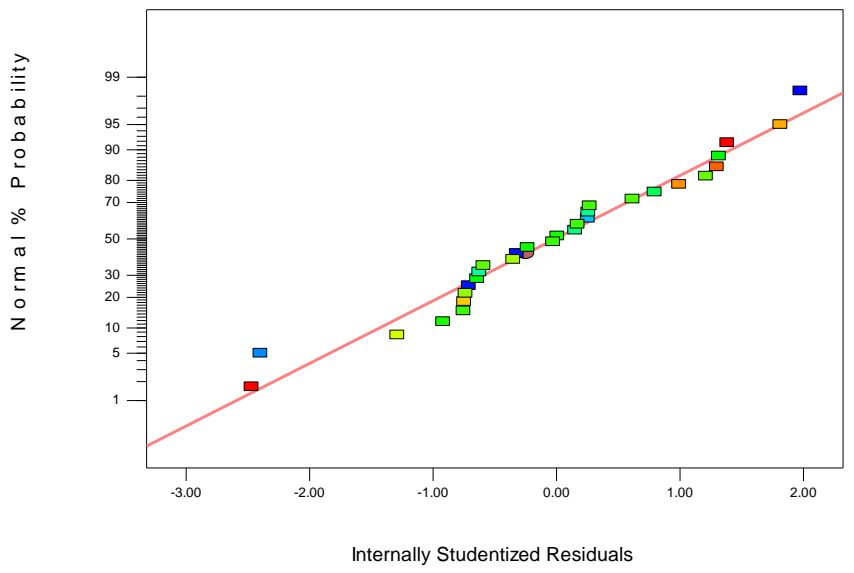

Figure 5. Residuals plot for RoC.

\subsubsection{Surface roughness (SR)}

Regression equation is in terms of coded parameters:

$\mathrm{SR}=1.47+0.34 \mathrm{~A}-0.19 \mathrm{~B}-0.12 \mathrm{C}-0.041 \mathrm{D}+0.022 \mathrm{CD}$

Regression equation is in terms of actual parameters:

$$
\begin{aligned}
\mathrm{SR} & =-2.679+0.04854 \mathrm{~A}-0.01864 \mathrm{~B}-0.01858 \mathrm{C} \\
& -0.05292 \mathrm{D}+0.001075 \mathrm{CD}
\end{aligned}
$$

\subsubsection{Radial overcut (RoC)}

Regression equation is in terms of coded parameters:

$$
\begin{aligned}
\text { RoC } & =19.7654+1.49889 \mathrm{~A}+0.76778 \mathrm{~B}-0.22556 \mathrm{C} \\
& +0.38889 \mathrm{D}-0.13 \mathrm{AB}+0.19875 \mathrm{AD}-0.32088 \mathrm{~A}^{2}
\end{aligned}
$$

Regression equation is in terms of actual parameters:

$$
\begin{aligned}
\mathrm{RoC} & =-94.5438+1.69975 \mathrm{~A}+0.454676 \mathrm{~B}-0.09212 \mathrm{C} \\
& -1.74364 \mathrm{D}-0.00186 \mathrm{AB}-0.00519 \mathrm{AD}-0.00655 \mathrm{~A}^{2}
\end{aligned}
$$

These predicted models were verified by conducting confirmation tests within the selected range of the WEDM parameters.

\subsection{Effect of WEDM parameters on performance characteristics}

Response surface graphs (Figs. 6 to 8 ) have been plotted to analyse the influence of WEDM parameters on performance characteristics, namely CS, SR and RoC. Surface plots have been plotted for combined effect of two factors while keeping other two factors at their mid-values.

\subsubsection{Effect of WEDM parameters on cutting speed}

Figure 6a to $\mathrm{c}$ show that cutting speed increases with increasing $T_{\text {on }}$ and WF, while it decreases with increasing $T_{\text {off }}$ and 


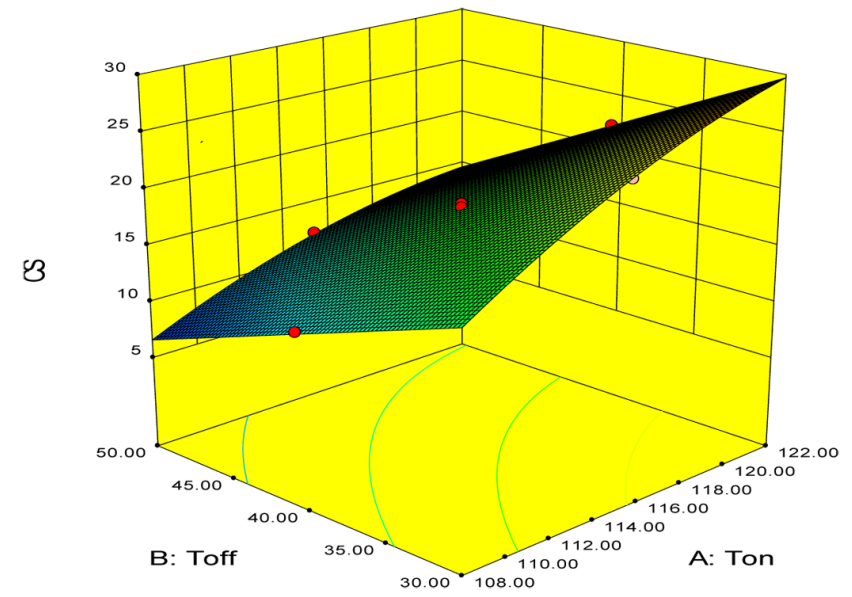

Figure 6a. Combined effect of $T_{\text {on }}$ and $T_{\text {off }}$ on CS.

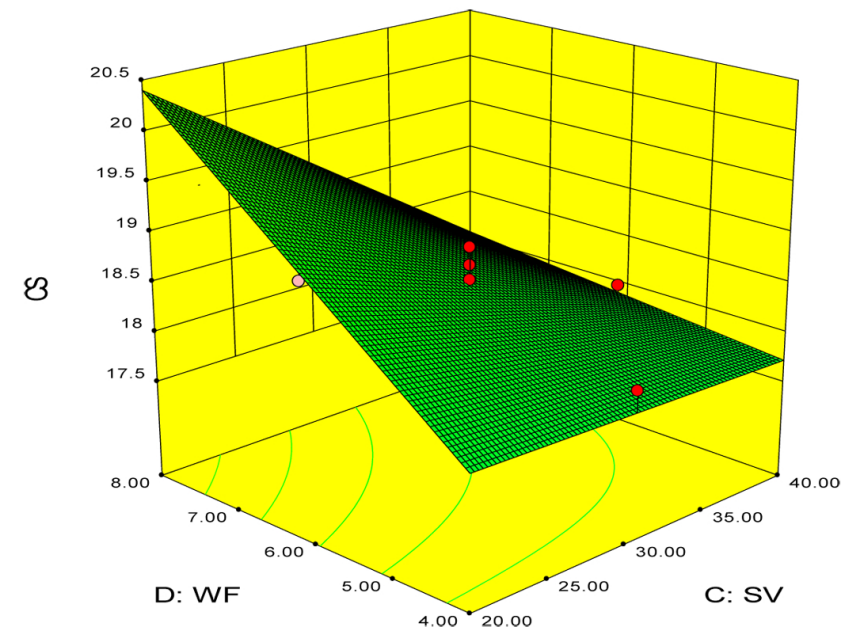

Figure 6b. Combined effect of SV and WF on CS.

SV. In WEDM, cutting speed depends on the melting of work surface and then flushing of the eroded material out of the spark zone. Melting of work surface depends on the thermal conductivity of work material and energy consumed per spark which is supposed to be the function of discharge current $\left(I_{p}\right)$, pulse duration $\left(T_{\text {on }}\right)$ and discharge voltage (SV) (Luo, 1995). Increasing pulse duration $\left(T_{\text {on }}\right)$ increases the heat generation at the work surface which increases the cutting speed. Decreasing servo voltage closes the spark gap which results in rapid and large ionization of dielectric fluid which gives rise to more melting of work material and hence increases the cutting speed.

The rise in cutting speed can be highly noticed at high value of wire feed. High discharge energy results in more melting and evaporation of the work material causing liberation of large number of carbide debrises which coagulates in the spark gap and hence affects the machining process by producing arcs. Increasing wire feed rate leads to the easy and rapid escape of the eroded material out of the spark gap

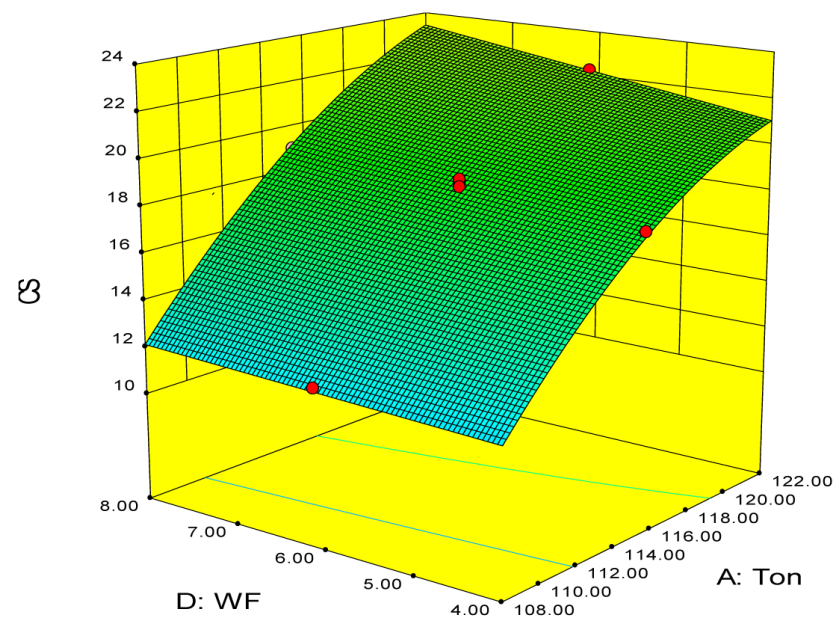

Figure 6c. Combined effects of $T_{\text {on }}$ and WF on CS.

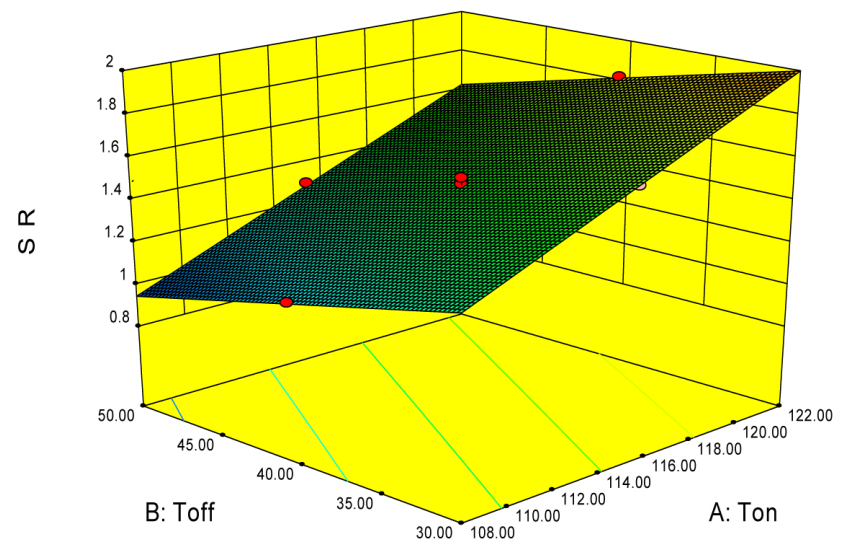

Figure 7a. Combined effects of $T_{\text {on }}$ and $T_{\text {off }}$ on SR.

and hence increases the cutting speed. This can be observed from the combined effect of WF with SV and $T_{\text {on }}$ as shown in Fig. 6b-c.

Increasing pulse-off time ( $\left.T_{\text {off }}\right)$ value decreases the discharge frequency and increases the overall machining time. Also long pulse-off time at high dielectric flow rate produces the cooling effect on work material and hence decreases the CS. The interaction among WEDM parameters $\left(T_{\text {on }}\right.$ and $T_{\text {off }}$; $\mathrm{SV}$ and WF) can be observed from curvature of the contour plots on response surface graphs. The low F-value $(<0.05)$ for these interactions effect shows a significant influence on performance characteristics as shown in Table 4.

\subsubsection{Effect of WEDM parameters on surface roughness}

Surface roughness increases with increasing pulse-on time $\left(T_{\text {on }}\right)$ and decreasing servo voltage (SV) as shown in Fig. 7ab. In WEDM, SR is mainly described by the shape and size of the surface craters which mainly depends on the discharge energy and re-deposition of melted material on work surface. 


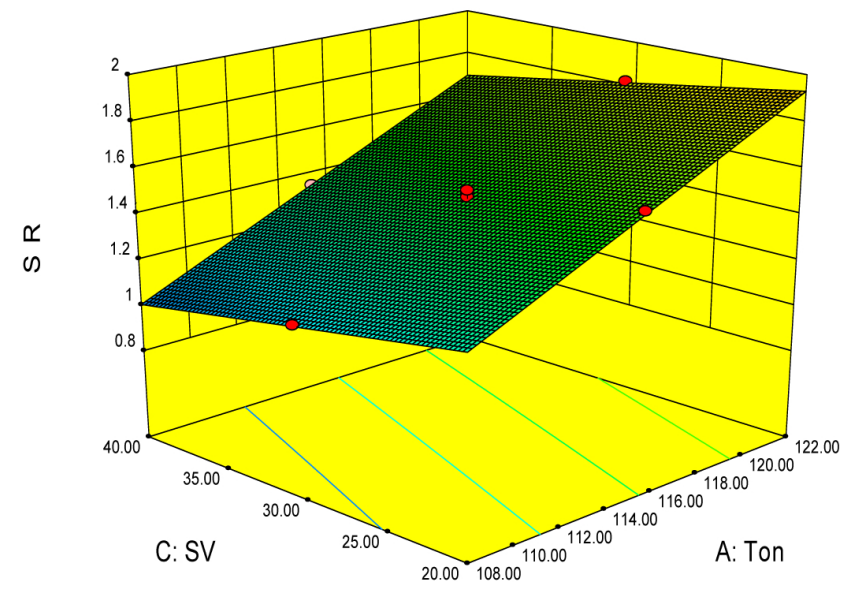

Figure $7 \mathrm{~b}$. Combined effects of $T_{\text {on }}$ and SV on SR.

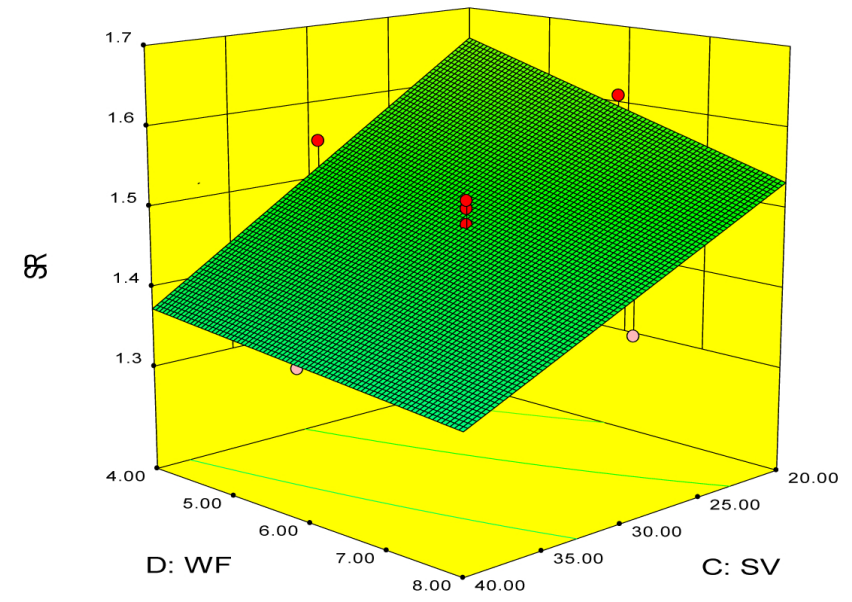

Figure 7c. Combined effects of SV and WF on SR.

Increasing pulse-on time and decreasing servo voltage increases the discharge energy across the electrodes which results in deeper erosion crater on the work surface and hence increases the surface roughness (Lee and Li, 2003).

Due to the large difference between melting temperatures for $\mathrm{WC}$ and $\mathrm{Co}$, discharge energy tends to melt, evaporate and remove cobalt even before the melting of WC. As a result WC grains may release without melting or in semi-solid state which coagulate in the spark gap (Saha et al., 2008). At high discharge energy, the probability of re-deposition of melted material of work surface is high. Increasing $T_{\text {off }}$-value increases the time between two consecutive sparks which results in complete flushing of the carbide debris out of the spark gap, and hence low re-deposition of eroded material results in low surface roughness as shown by the combined effect of $T_{\text {on }}$ and $T_{\text {off }}$ in Fig. 7a.

Surface roughness shows mild tendency to decrease with increasing wire feed rate (WF) as shown in Fig. 7c. Increasing wire feed results in easy escape of carbide debris out of the spark gap which results in low re-deposition of melted

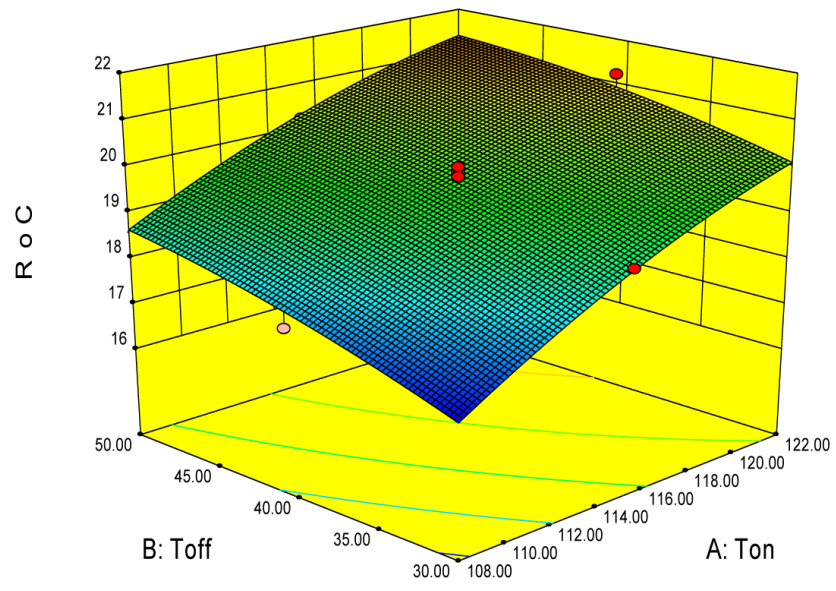

Figure 8a. Combined effects of $T_{\text {on }}$ and $T_{\text {off }}$ on RoC.

residuals and hence low surface roughness. Curved contour on response graphs between WF and SV shows some interaction between these parameters. To get good surface finish, it is desirable to keep the electrical discharging energy at smaller level, by setting low $T_{\text {on }}$ and high $T_{\text {off }}$-value.

\subsubsection{Effect of WEDM parameters on radial overcut}

RoC is the thickness of material removed perpendicular to the cutting direction as shown in Fig. 2. RoC helps to achieve accurate wire offset for rough cutting operation for obtaining precise dimensional tolerance. $\mathrm{RoC}$ depends on the amount of material melted and flushing it out of the spark gap. Increasing pulse-on time $\left(T_{\text {on }}\right)$ results in high discharge energy which causes more melting and erosion of work surface which increases the RoC. At high value of pulse-off time $\left(T_{\text {off }}\right)$, eroded carbide debris is easily flushed away from the spark gap. Therefore, RoC increases with increase in $T_{\text {on }}$ and $T_{\text {off }}$ as shown by surface plots in Fig. 8a, c and d. At low value of $T_{\text {off }}$, tendency of recasting of residue material on the work surface is high, which decreases the RoC.

Increasing wire feed rate helps to clear off the spark gap quickly which results in low re-deposition of eroded material and hence increases the RoC as shown in Fig. 8b. Decreasing servo voltage (SV) results in more ionization of the spark gap which results in more melting of work material and hence increases the RoC. Curved contours on response graph show the interaction between WEDM parameters. Using response surface graphs, values of WEDM parameters can be selected for the desired value of performance characteristics.

\section{Conclusions}

In present work, experimental investigation has been reported on machining performance of WC-5.3\% Co composite on WEDM. Response surface methodology (RSM), a statistical technique, has been utilised to investigate the 


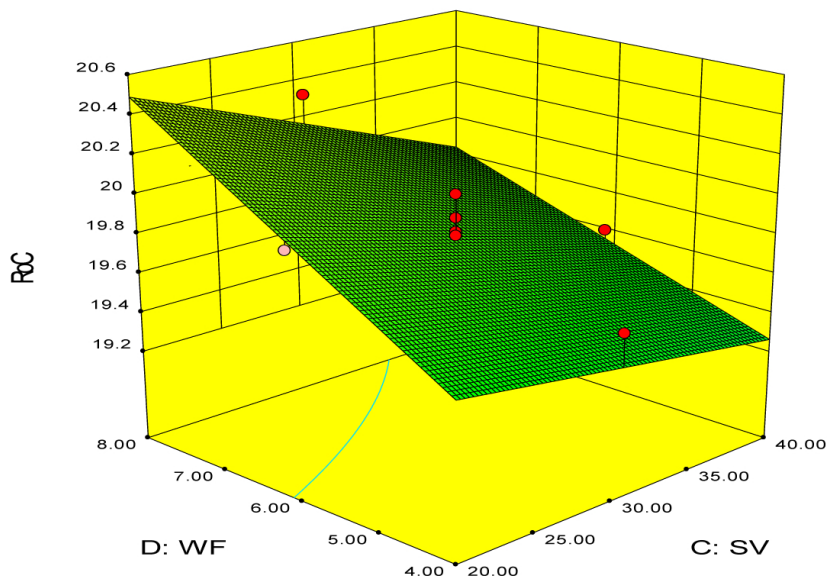

Figure 8b. Combined effects of SV and WF on RoC.

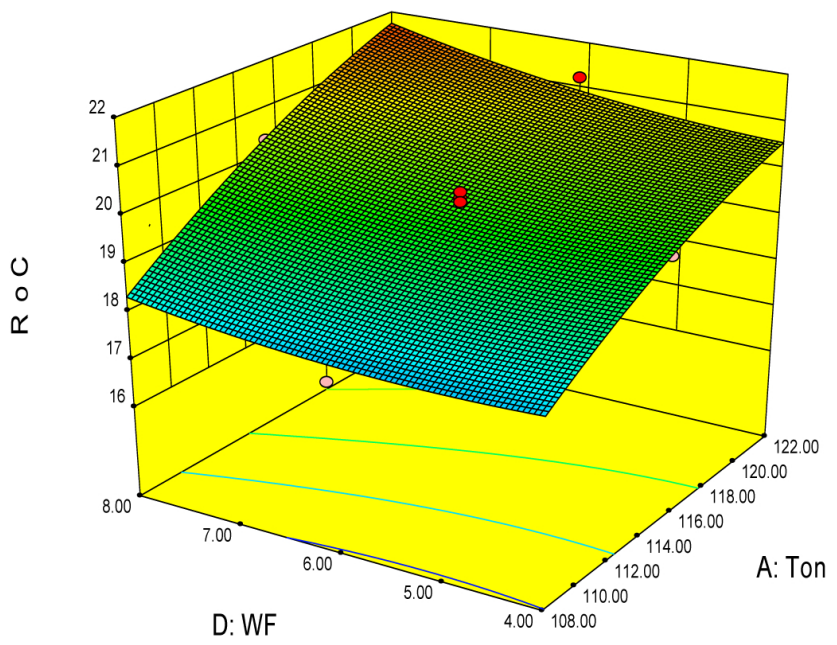

Figure 8c. Combined effects of $T_{\text {on }}$ and WF on RoC.

influence of four important WEDM parameters - pulse-on time $\left(T_{\text {on }}\right)$, pulse-off time $\left(T_{\text {off }}\right)$, servo voltage $(\mathrm{SV})$ and wire feed (WF) - on three performance characteristics: cutting speed (CS), surface roughness (SR) and radial overcut (RoC). Face centered central composite design was employed to conduct the experiments and to develop a correlation between the WEDM parameters and each performance characteristics. Analysis of variance (ANOVA) on experimental data shows that quadratic vs. two-factor interaction (2FI) model as the best fit for CS and RoC, while two-factor interaction (2FI) has been proposed for SR.

Response surface graphs were used to describe the influence of WEDM parameters on each performance characteristic. $T_{\mathrm{on}}, T_{\mathrm{off}}, \mathrm{SV}$ and WF produce significant influence on each performance characteristic. In case of cutting speed, interaction between $T_{\text {on }}$ and $T_{\text {off }} ; T_{\text {on }}$ and WF; $T_{\text {off }}$ and WF; SV and WF produces significant effect, while, in SR, interaction effect of SV and WF has been found significant. In case of RoC, interaction among $T_{\text {on }}$ and $T_{\text {off }}$;

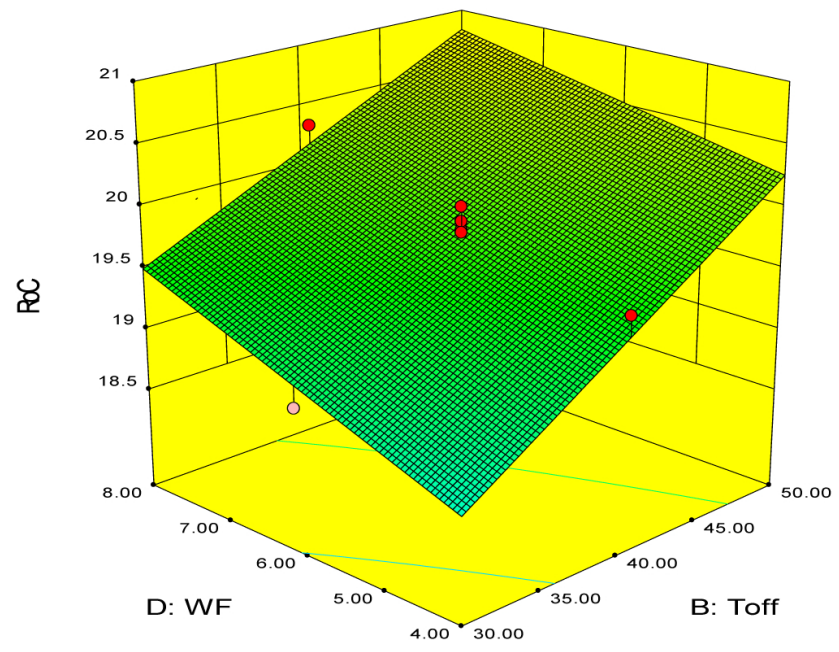

Figure 8d. Combined effects of WF and $T_{\text {off }}$ on RoC.

$T_{\mathrm{on}}$ and WF produces significant effect. Using mathematical models, optimal parameters can be determined easily for desired performance characteristics. Hence a trade-off can be made among various performance characteristics.

Edited by: B. Azarhoushang

Reviewed by: two anonymous referees

\section{References}

Çaydaş, U., Hasçalik, A., and Ekici, S.: An adaptive neuro-fuzzy inference system (ANFIS) model for wire-EDM, Expert Syst. Appl., 36, 6135-6139, 2009.

Chen, H.-C., Lin, J.-C., Yang, Y.-K., and Tsai, C.-H.: Optimization of wire electrical discharge machining for pure tungsten using a neural network integrated simulating annealing approach, Expert Syst. Appl., 37, 7147-7153, 2010.

Cochran, G. and Cox, G. M.: Experimental design, Asia Publishing House, New Delhi, 1962.

Engqvist, H., Ederyd, S., and Axen, N.: Grooving wear of singlecrystal tungsten carbide, Wear, 230, 165-174, 1999.

Hewidy, M. S., El-Taweel, T. A., and El-Safty, M. F.: Modeling the machining parameters of wire electrical discharge machining of Inconel 601 using RSM, J. Mater. Process. Tech., 169, 328-336, 2005.

Jangra, K.: Study of unmachined area in intricate machining after rough cut in WEDM, Int. J. Indust. Eng. Comput., 3, 887-892, 2012.

Jangra, K., Jain, A., and Grover, S.: Optimization of multiplemachining characteristics in wire electrical discharge machining of punching die using grey relational analysis, J. Sci. Ind. Res., 69, 606-612, 2010.

Jangra, K., Grover, S., Chan, F. T. S., and Aggarwal, A.: Digraph and matrix method to evaluate the machinability of tungsten carbide composite with wire EDM, Int. J. Adv. Manuf. Tech., 56, 959-974, 2011.

Jangra, K., Grover, S., and Aggarwal, A.: Optimization of multi machining characteristics in WEDM of WC-5.3\% Co composite 
using integrated approach of Taguchi, GRA and Entropy method, Frontiers of Mechanical Engineering, 7, 288-299, 2012.

Jia, K. and Fischer, T. E.: Sliding wear of conventional and nanostructured cemented carbides, Wear, 203-204, 310-318, 1997.

Kanagarajan, D., Karthikeyan, R., Palanikumar, K., Paulo, and Davim, J.: Optimization of electrical discharge machining characteristics of WC/Co composites uing non-dominated sorting genetic algorithm (NSGA-II), Int. J. Adv. Manuf. Tech., 36, 11241132, 2008.

Kansal, H. K., Singh, S., and Kumar, P.: Parametric optimization of powder mixed electrical discharge machining by response surface methodology, J. Mater. Process. Tech., 169, 427-436, 2005.

Kim, C. H. and Kruth, J. P.: Influence of electrical conductivity of dielectrical fluid on WEDM of sintered carbide, KSME Int. J., 15, 1276-1282, 2001.

Lauwers, B., Liu, W., and Eeraerts, W.: Influence of the composition of WC-based cermets on manufacturability by wire-EDM, J. Mater. Process. Tech., 8, 83-89, 2006.

Lee, S. H. and Li, X. P.: Study of the effect of machining parameters on the machining characteristics in electrical discharge machining of tungsten carbide, J. Mater. Process. Tech., 115, 344-358, 2001.

Lee, S. H. and Li, X. P.: Study of the surface integrity of the machined workpiece in the EDM of tungsten carbide, J. Mater. Process. Tech., 139, 315-321, 2003.
Liu, K. and Li, X. P.: Ductile cutting of tungsten carbide, J. Mater. Process. Tech., 113, 348-354, 2001.

Liu, K., Li, X. P., and Rahman, M.: Characteristics of high speed micro cutting of tungsten carbide, J. Mater. Process. Tech., 140, 352-357, 2003.

Luo, Y. F.: An energy-distribution strategy in fast cutting wire EDM, J. Mater. Process. Tech., 55, 380-390, 1995.

Mahdavinejad, R. A. and Mahdavinejad, A.: ED machining of WCCo, J. Mater. Process. Tech., 162-163, 637-643, 2005.

Myers, R. H. and Montgomery, D. C.: Response Surface Methodology, New York, Wiley, 11, 535-561 and 12, 570-615, 1995.

Patil, N. G. and Brahmankar, P. K.: Determination of material removal rate in wire electro-discharge machining of metla matrix composites using dimensional analysis, Int. J. Adv. Manuf. Tech., 51, 599-610, 2010.

Saha, P., Singha, A., and Pal, S. K.: Soft computing models based prediction of cutting speed and surface roughness in wire electrodischarge machining of tungsten carbide cobalt composite, Int. J. Adv. Manuf. Tech., 39, 74-84, 2008.

Sarkar, S., Sekh, M., Mitra, S., and Bhattacharyya, B.: Modelling and optimization of wire electrical discharge machining of $\gamma$ TiAl in trim cutting operation, J. Mater. Process. Tech., 205, 376387, 2008. 